\title{
Use of continuous flow ventricular assist devices in patients with heart failure and a normal ejection fraction: A computer-simulation study
}

\author{
Francesco Moscato, PhD, ${ }^{\mathrm{a}, \mathrm{c}}$ Christian Wirrmann, ${ }^{\mathrm{a}, \mathrm{c}}$ Marcus Granegger, MSc, ${ }^{\text {a,c }}$ Farsad Eskandary, MD, \\ Daniel Zimpfer, MD, ${ }^{\mathrm{b}}$ and Heinrich Schima, $\mathrm{PhD}^{\mathrm{a}, \mathrm{b}, \mathrm{c}}$
}

\begin{abstract}
Objectives: Continuous flow left ventricular assist devices are used in end-stage systolic heart failure. However, about one half of the patients with heart failure exhibit diastolic dysfunction with a normal ejection fraction. In the present study, the possible hemodynamic consequences of continuous flow left ventricular assist devices use for these patients were investigated.
\end{abstract}

\begin{abstract}
Methods: A previously developed cardiovascular model was modified to reproduce the peculiar hemodynamics of heart failure with a normal ejection fraction. The model was based on and validated with patient data derived from the published data. A continuous flow left ventricular assist device model was included and the hemodynamic effects of pump support evaluated at rest and during exercise.
\end{abstract}

Results: The model accurately reproduced the published data both at rest and during exercise, leading to simulated hemodynamic values within the standard deviations of patient variability. At rest, pump support decreased the end-diastolic left ventricular pressure ( 6 vs $15 \mathrm{~mm} \mathrm{Hg}$ ) and volume ( $88 \mathrm{vs} 135 \mathrm{~mL}$ ). During exercise, maximal pump support substantially unloaded the left ventricle (end-diastolic pressure, $14 \mathrm{vs} 35 \mathrm{~mm} \mathrm{Hg}$; volume, 133 vs $158 \mathrm{~mL}$ ) and the pulmonary venous circulation (left atrial pressure, 12 vs $24 \mathrm{~mm} \mathrm{Hg}$ ) and resulted in a slight increase in cardiac output (11.7 vs $9.9 \mathrm{~L} / \mathrm{min})$.

Conclusions: The simulation results suggested that continuous flow left ventricular assist devices improve the hemodynamics in patients with heart failure and a normal ejection fraction. For an optimal use of continuous flow left ventricular assist devices, low speeds should be maintained at rest, to avoid suction. However, during physical activity, higher speeds are needed to prevent an abnormal increase in the ventricular filling pressures typical of patients with heart failure and a normal ejection fraction. (J Thorac Cardiovasc Surg 2013;145:1352-8)

The use of a continuous flow left ventricular (LV) assist device (CF-LVAD) has recently become the standard treatment of patients with end-stage heart failure, with tremendous improvement in mortality and morbidity. ${ }^{1,2}$ Typically, CF-LVADs are implanted in patients with dilated or ischemic cardiomyopathy, characterized by severe LV systolic dysfunction with reduced ejection fraction. For example, in the study by Slaughter and colleagues, ${ }^{1}$ a CF-LVAD was implanted in 134 patients with heart failure with a preimplant $\mathrm{LV}$ ejection fraction of $17 \% \pm 5.5 \%$.

However, in the past 2 decades, epidemiologic studies have shown that about one half of the patient population presenting with symptoms and signs of heart failure,

\footnotetext{
From the Center for Medical Physics and Biomedical Engineering ${ }^{\mathrm{a}}$ and Department of Cardiac Surgery, ${ }^{\mathrm{b}}$ Medical University of Vienna, Vienna, Austria; and Ludwig Boltzmann Cluster for Cardiovascular Research, ${ }^{\mathrm{c}}$ Vienna, Austria.

This work was supported in part by the Österreichische Nationalbank Jubiläumsfonds (Jubiläumsfondsprojekt no. 13692).

Disclosures: Authors have nothing to disclose with regard to commercial support. Received for publication March 13, 2012; revisions received May 18, 2012; accepted for publication June 18, 2012; available ahead of print July 27, 2012.

Address for reprints: Francesco Moscato, PhD, Center for Medical Physics and Biomedical Engineering, Medical University of Vienna, AKH-4L, Waehringer Guertel 18-20, Vienna 1090, Austria (E-mail: francesco.moscato@meduniwien.ac.at). $0022-5223 / \$ 36.00$

Copyright (c) 2013 by The American Association for Thoracic Surgery http://dx.doi.org/10.1016/j.jtcvs.2012.06.057
}

especially the elderly and women, have a normal ejection fraction (ejection fraction, $\geq 50 \%$ ). This condition is usually termed "heart failure with a normal ejection fraction" (HFNEF). ${ }^{3,4}$ Patients with HFNEF are characterized by an alteration of the LV diastolic function with prolonged relaxation and reduced ventricular compliance. These alterations lead to an elevated LV diastolic pressure, a blunted diastolic function reserve with a small increase in the end-diastolic volume, despite a marked increase in ventricular filling pressures, a depressed chronotropic reserve, and exercise intolerance. ${ }^{4}$ Unfortunately, current therapeutic treatment strategies for patients with HFNEF have not increased the survival rates. ${ }^{3,4}$ Patients with HFNEF are not yet necessarily considered for CF-LVAD implantation and when disease progresses to end-stage heart failure, they have a poor prognosis, with heart transplantation the only curative treatment option.

Since CF-LVADs have proved their ability to fully restore body perfusion and to unload the failing left ventricle and the pulmonary circulation in the past 10 years, ${ }^{1,5}$ it seems reasonable to investigate whether patients with HFNEF could also benefit from mechanical assistance. We, thus, hypothesized that CF-LVADs can facilitate ventricular filling, which is otherwise compromised in these patients, and, consequently, unload the pulmonary circulation. This 


\section{Abbreviations and Acronyms \\ CF- = continuous flow left ventricular assist \\ LVAD device \\ EDP = end-diastolic pressure \\ $\mathrm{EDV}=$ end-diastolic volume \\ EDPVR $=$ end-diastolic pressure-volume relationship \\ HFNEF $=$ heart failure with a normal ejection fraction \\ LAP $\quad=$ left arterial pressure \\ LV $=$ left ventricular \\ NYHA $=$ New York Heart Association}

would thus represent a potential option for symptom reduction and improved exercise tolerance. In the present study, the unloading effects of a CF-LVAD were evaluated in a computer simulation of the hemodynamics of HFNEF patients and compared with an unassisted case, both at rest and during physical activity.

\section{METHODS}

We describe the computer model of the cardiovascular system, adapted to reproduce the hemodynamics observed in patients with HFNEF and of a centrifugal CF-LVAD. Additionally, the published data used for comparison and validation of the simulation results are presented. Finally, the simulation of the HFNEF model, including the CF-LVAD, is described, along with the key questions and hypotheses addressed by the simulation.

\section{Hemodynamic Model of HFNEF and Cardiovascular Response to Exercise}

A previously developed numeric model of the cardiovascular system ${ }^{6,7}$ has been modified to reproduce the peculiar hemodynamics of patients with HFNEF both at rest and during physical activity. The model was implemented using Matlab-Simulink (The MathWorks Inc, Natick, Mass) and comprised a hydraulic closed loop with active atria and ventricles, systemic and pulmonary circulation, and autonomic control mechanisms. A schematic diagram of the model structure is shown in Figure 1. The modifications to the previous model are briefly discussed: these consisted of the adaptation of the ventricular end-diastolic, end-systolic, and relaxation properties to patients with HFNEF and in the implementation of the hemodynamic response to exercise of these patients.

The LV end-diastolic pressure-volume relationship (EDPVR) was modeled with an exponential function. ${ }^{8}$ The LV end-systolic pressure-volume relationship was modeled as the sum of the EDPVR and a parabolic function. ${ }^{9}$ The normalized elastance function has been simplified to a biexponential function, which allowed the straightforward adjustment of the time constant of ventricular pressure relaxation. The parameters of the ventricular EDPVR, and normalized elastance function were chosen to reproduce the end-diastolic pressures and volumes and the time course of LV pressures as reported in previous studies. ${ }^{10-13}$

The cardiovascular response to exercise was modeled as the interaction between the central command, which modulates parasympathetic withdrawal and sympathetic activation by way of a reset of the arterial baroreflex operating point, and the mechanosensitive and metabolically sensitive skeletal muscle afferents, which regulate peripheral vasodilatation. ${ }^{14}$ In the present model, these mechanisms were implemented at the onset of exercise by an increase of the pressure set point for the baroreflex of $30 \%$ from the initial value of $110 \mathrm{~mm} \mathrm{Hg}$ (central command action) and by a decrease of the peripheral resistance of $50 \%$ from the initial value of $1.04 \mathrm{~mm}$ $\mathrm{Hg} \cdot \mathrm{s} / \mathrm{mL}$ (mechanosensitive and metabolically sensitive skeletal muscle afferents action). The apparent hypotension caused by the set point increase and the peripheral resistance decrease led to a baroreflex-mediated increase of the heart rate and contractility to a reduction of the systemic venous unstressed volume and systemic vascular constriction. This latter effect, however, combined with the skeletal muscle afferent vasodilatation, resulted in a net vasodilatation in the model. The baroreflex system was modeled using the structure described by Ursino and Magosso, ${ }^{15}$ with parameter values adapted to match the heart rate, mean arterial pressure, cardiac output (CO), and peripheral resistance response of patients with HFNEF. ${ }^{16,17}$

\section{Model of CF-LVAD}

A computer model of a centrifugal rotary blood pump and its cannulas were used in the present study. The hydrodynamic model of the CF-LVAD was derived from mock loop experiments, according to a procedure described by Moscato and colleagues. ${ }^{18}$ The validity of the model covered the usual clinical working ranges with pump speeds of 1.8 to $4.0 \mathrm{krpm}$, pump flow of 0 to $10 \mathrm{~L} / \mathrm{min}$, and differential pressure of 0 to $150 \mathrm{~mm} \mathrm{Hg}$.

\section{Published Data Used for Model Comparison and Validation}

The model simulation results were compared with the published data of HFNEF patients. From a PubMed search using the keywords "heart failure with normal ejection fraction," 10 studies ${ }^{10-13,16,17,19-22}$ were selected because of their similar patient inclusion and exclusion criteria (presence of heart failure symptoms and ejection fraction $>50 \%$ and the absence of heart valve disease, heart rhythm disease, and pulmonary disease) and patient demographics. The pooled demographics for the 243 patients included age, $60.4 \pm 9.4$ years, female gender $56.9 \% \pm 18.0 \%$, body mass index $29.7 \pm 4.4 \mathrm{~kg} / \mathrm{m}^{2}$, New York Heart Association (NYHA) class II in $61.2 \% \pm 18.1 \%$, and NYHA class III in $38.8 \% \pm 16.0 \%$. The pooled mean and variance were calculated from the hemodynamic variables reported in the published data, both at rest and during exercise, and were used for comparison with the simulation results. The hemodynamic variables, which were given in the published studies as normalized by body surface area (eg, cardiac index), were converted to non-normalized values (eg, $\mathrm{CO}$ ) using the body surface area calculated with Mosteller's formula. Thus, the body weight was determined by the body mass index reported in the studies, and the body height was derived from averaged age- and gender-matched population data. In 1 study, the hemodynamic values were given as the median and range ${ }^{12}$ and in another study as the median and interquartile range, ${ }^{13}$ thus requiring an estimation of the mean and standard deviation before pooling. ${ }^{23}$

\section{Simulation of CF-LVAD Support in the Case of HFNEF}

The CF-LVAD model was included in the HFNEF cardiovascular model, and a simulation was performed to investigate the effects of mechanical assistance on LV filling. The main hypothesis addressed by the simulation was that the CF-LVAD will leads to a ventricular filling pressure decrease, just as it does in the case of systolic heart failure support. In addition, the effectiveness of a constant speed support was investigated during both rest and exercise conditions. In particular, we investigated whether a constant speed for rest and exercise would be sufficient to guarantee adequate unloading of the heart and the pulmonary venous circulation in both cases. The at rest and exercise conditions were simulated without pump support and with 3 different pump support settings (pump speed, 2.5, 3.0, and $3.5 \mathrm{krpm}$ ). The key hemodynamic variables, such as the ventricular filling pressure and volume and $\mathrm{CO}$, were compared for the unsupported condition and pump-supported condition at the 3 different speeds. 


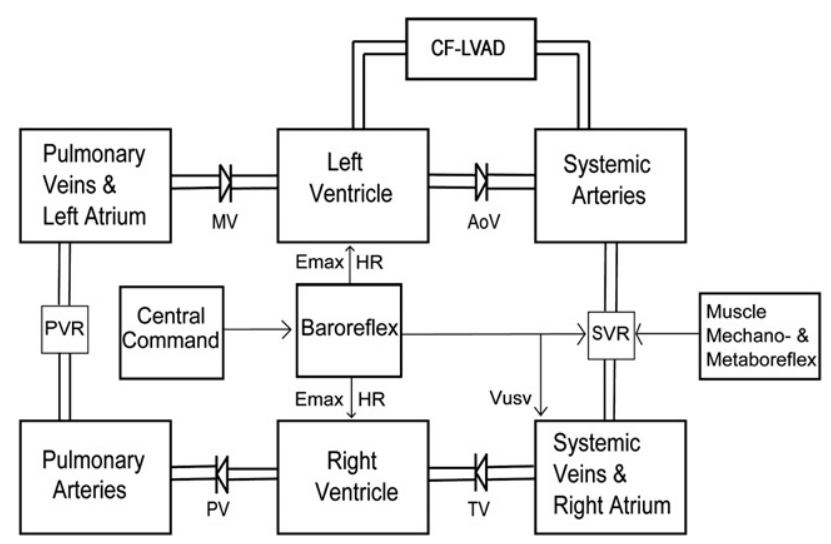

FIGURE 1. Schematic diagram of the hemodynamic model structure, including the systemic and pulmonary circulation, continuous flow left ventricular assist device (CF-LVAD), central command, baroreflex and muscle mechanoreflex and metabolic reflex. $M V$, Mitral valve; $A o V$, aortic valve; $T V$, tricuspid valve; $P V$, pulmonary valve; $S V R$, systemic vascular resistance; $P V R$, pulmonary vascular resistance; Vusv, unstressed volume in the systemic veins; Emax, maximal ventricular elastance; $H R$, heart rate.

\section{RESULTS}

Figure 2, $A$ and $B$, show the simulated pressure-volume loop and EDPVR in the presence of a normal healthy ventricle and HFNEF. The remarkable shift of the EDPVR toward greater pressures at relatively normal volumes can be observed, reflecting the increased ventricular stiffness characteristic for patients with HFNEF. Figure 2, $C$ and $D$, show the pressure and flow waveforms for healthy and HFNEF conditions. In the HFNEF condition, a delayed relaxation with a prolonged LV pressure time constant can be noted ( $\tau=54$ vs $24 \mathrm{~ms}$ ), as well as a change in the shape of the transmitral blood flow. The latter is characterized by a slower $\mathrm{E}$ wave deceleration time, reflecting impaired relaxation, and an increased contribution to filling of the A wave, reflecting the compensatory atrial contribution to the impaired early diastolic filling.

The results of the comparison of the hemodynamic data calculated from the numeric simulation and published data are listed in Table 1. The relevant data for this comparison are also shown in the histogram plots of Figure 3. The simulation was able to reproduce the published data very well, confirming the ability of the model to represent the peculiar hemodynamics of patients with HFNEF both at rest and during exercise. In the simulation, the heart rate increased with exercise from 69 to 103 beats/min (published data, from $71 \pm 9$ to $103 \pm 14$ beats/min), the LV enddiastolic pressure (EDP) increased remarkably from 15 to $35 \mathrm{~mm} \mathrm{Hg}$ (published data, $18 \pm 4$ to $34 \pm 6 \mathrm{~mm} \mathrm{Hg}$ ), and the LV end-diastolic volume (EDV) increased from 135 to $158 \mathrm{~mL}$ (published data, $143 \pm 23$ to $158 \pm 50$ $\mathrm{mL}$ ). In the simulation, as a result of exercise, the systemic arterial pressure (SAP) increased from 106 to $125 \mathrm{~mm} \mathrm{Hg}$ (published data, $105 \pm 14$ to $123 \pm 14 \mathrm{~mm} \mathrm{Hg}$ ), the left
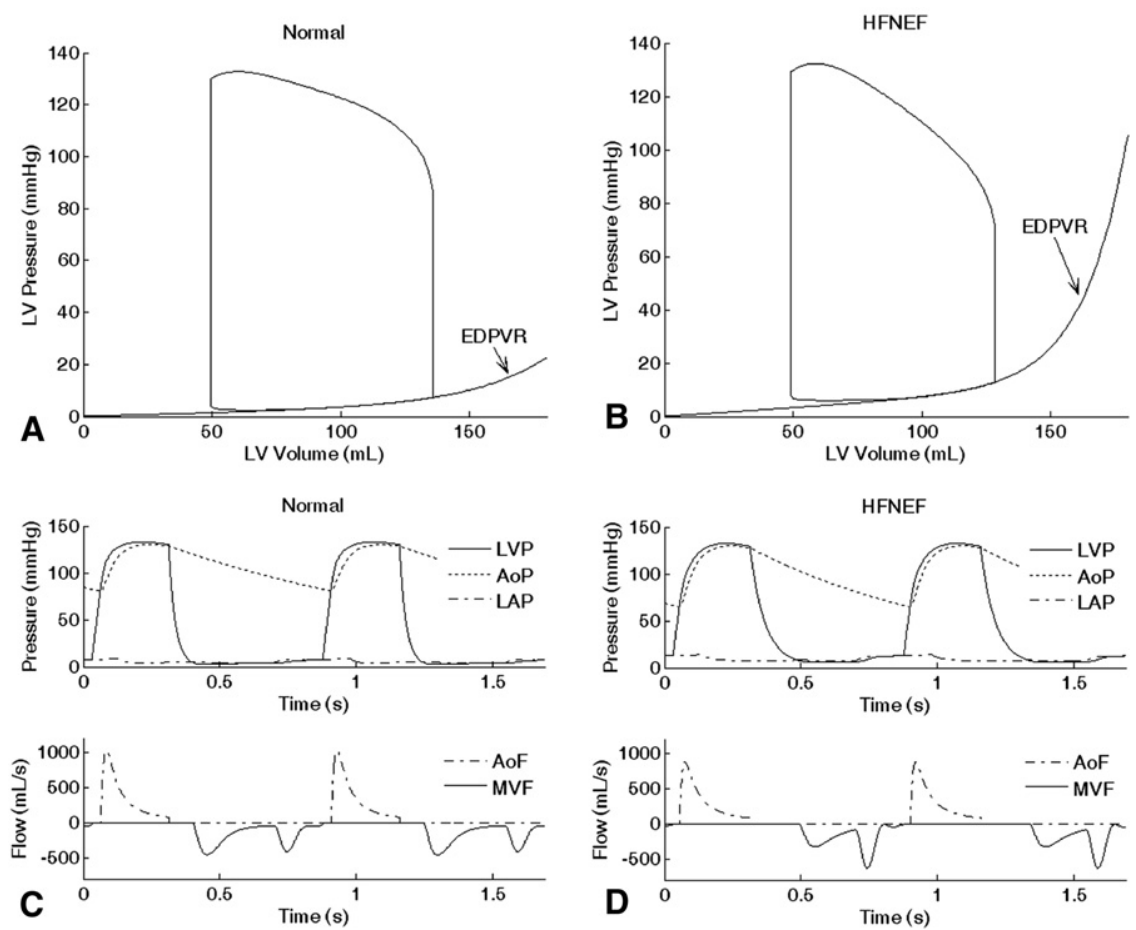

FIGURE 2. Simulation results for the pressure-volume loops for A, a normal condition and B, heart failure with normal ejection fraction (HFNEF). Simulation results for the pressure and flow tracings for $\mathrm{C}$, a normal condition and $\mathrm{D}$, heart failure with normal ejection fraction. AoF, Aortic flow; $A o P$, aortic pressure; $E D P V R$, end-diastolic pressure volume relationship; $L A P$, left atrial pressure; $L V P$, left ventricular pressure; $M V F$, mitral valve flow. 
TABLE 1. Comparison of hemodynamic data derived from pooled published data and from model simulation without CF-LVAD assistance

\begin{tabular}{|c|c|c|c|c|}
\hline \multirow[b]{2}{*}{ Variable } & \multicolumn{2}{|l|}{ At rest } & \multicolumn{2}{|c|}{ Exercise } \\
\hline & Published data* $(n=264)$ & Model & Published data $\nmid(n=46)$ & Mode \\
\hline HR (beats/min) & $71 \pm 9$ & 69 & $103 \pm 14$ & 103 \\
\hline $\mathrm{CO}(\mathrm{L} / \mathrm{min})$ & $6.26 \pm 0.85$ & 5.68 & $9.55 \pm 1.96$ & 9.92 \\
\hline $\mathrm{SV}(\mathrm{mL})$ & $87 \pm 15$ & 84 & $92 \pm 20$ & 97 \\
\hline $\mathrm{EDV}(\mathrm{mL})$ & $143 \pm 23$ & 135 & $158 \pm 50 \ddagger$ & 158 \\
\hline ESV (mL) & $55 \pm 18$ & 51 & $66 \pm 45 \S$ & 61 \\
\hline $\mathrm{EF}(\%)$ & $65 \pm 12$ & 62 & $58 \pm 22$ & 61 \\
\hline $\mathrm{EDP}(\mathrm{mm} \mathrm{Hg})$ & $18 \pm 4$ & 15 & $34 \pm 6$ & 35 \\
\hline $\mathrm{ESP}(\mathrm{mm} \mathrm{Hg})$ & $136 \pm 17$ & 135 & $158 \pm 17$ & 170 \\
\hline $\mathrm{SAP}(\mathrm{mm} \mathrm{Hg})$ & $105 \pm 14$ & 106 & $123 \pm 14$ & 125 \\
\hline SBP (mm Hg) & $147 \pm 16$ & 140 & $179 \pm 17$ & 171 \\
\hline $\mathrm{DBP}(\mathrm{mm} \mathrm{Hg})$ & $82 \pm 18$ & 69 & $96 \pm 23$ & 75 \\
\hline PAP (mm Hg) & $19 \pm 3$ & 21 & $41 \pm 6$ & 39 \\
\hline PCWP (mm Hg) & $15 \pm 7$ & 119 & $26 \pm 4$ & 249 \\
\hline RAP (mm Hg) & $6 \pm 2$ & 4 & $14 \pm 4$ & 6 \\
\hline $\mathrm{SVR}(\mathrm{mm} \mathrm{Hg} \cdot \mathrm{s} / \mathrm{mL})$ & $1.04 \pm 0.21$ & 1.08 & $0.76 \pm 0.26$ & 0.72 \\
\hline $\operatorname{PVR}(\mathrm{mm} \mathrm{Hg} \cdot \mathrm{s} / \mathrm{mL})$ & $0.10 \pm 0.07$ & 0.11 & $0.08 \pm 0.05$ & 0.09 \\
\hline$\tau(\mathrm{ms})$ & $54 \pm 8$ & 54 & - & 54 \\
\hline
\end{tabular}

$C O$, Cardiac output; $D B P$, diastolic arterial pressure; $E D P$, end-diastolic pressure; $E D V$, end-diastolic volume; $E F$, ejection fraction; $E S P$, end-systolic pressure; $E S V$, end-systolic volume; $H R$, heart rate; $P A P$, pulmonary arterial pressure; $P C W P$, pulmonary capillary wedge pressure; $P V R$, pulmonary vascular resistance; $R A P$, right atrial pressure; $S B P$, systolic arterial pressure; $S V$, stroke volume; $S V R$, systemic vascular resistance; $\tau$, time constant of left ventricular pressure relaxation; $S A P$, systemic arterial pressure. $*$ Pooled data from Zile and colleagues, ${ }^{10}$ Penicka and colleagues, ${ }^{11}$ Westermann and colleagues, ${ }^{12}$ Kasner and colleagues, ${ }^{13}$ Maeder and colleauges, ${ }^{16}$ Borlaug and colleagues, ${ }^{17}$ Kawaguchi and colleagues, ${ }^{19}$ Drazner and colleagues, ${ }^{20}$ Baicu and colleagues, ${ }^{21}$ and Borlaug and colleagues. ${ }^{22} \dagger$ Pooled data from Maeder and colleagues ${ }^{16}$ and Borlaug and colleagues. ${ }^{17} \ddagger$ Values calculated from ESV and SV. $\S$ Values calculated from the ESP and ventricular end systolic elastance. $\uparrow$ Left atrial pressure used for comparison.

atrial pressure (LAP) increased from 11 to $24 \mathrm{~mm} \mathrm{Hg}$ (published data, pulmonary capillary wedge pressure $15 \pm 7$ to $26 \pm 4 \mathrm{~mm} \mathrm{Hg}$ ), and the $\mathrm{CO}$ increased from 5.68 to 9.92 $\mathrm{L} / \mathrm{min}$ (published data, $6.26 \pm 0.85$ to $9.55 \pm 1.96 \mathrm{~L} / \mathrm{min}$ ).

The relevant hemodynamic changes induced by the CF-LVAD are shown both at rest and during exercise in Figure 4. The unsupported condition was compared with the results obtained with the CF-LVAD running at the 3 different speeds. The results for the greatest speed $(3.5$ $\mathrm{krpm})$ at rest are not shown because the ventricular pressure decreased toward 0 , leading to completely emptied chambers and to a probable occurrence of ventricular or atrial suction. During exercise, the inclusion of the CF-LVAD in the HFNEF model compared with the unsupported condition led to a strong reduction of EDP (14 vs $35 \mathrm{~mm} \mathrm{Hg}$ ), LAP (12 vs $24 \mathrm{~mm} \mathrm{Hg}$ ), and EDV (133 vs $158 \mathrm{~mL}$ ),
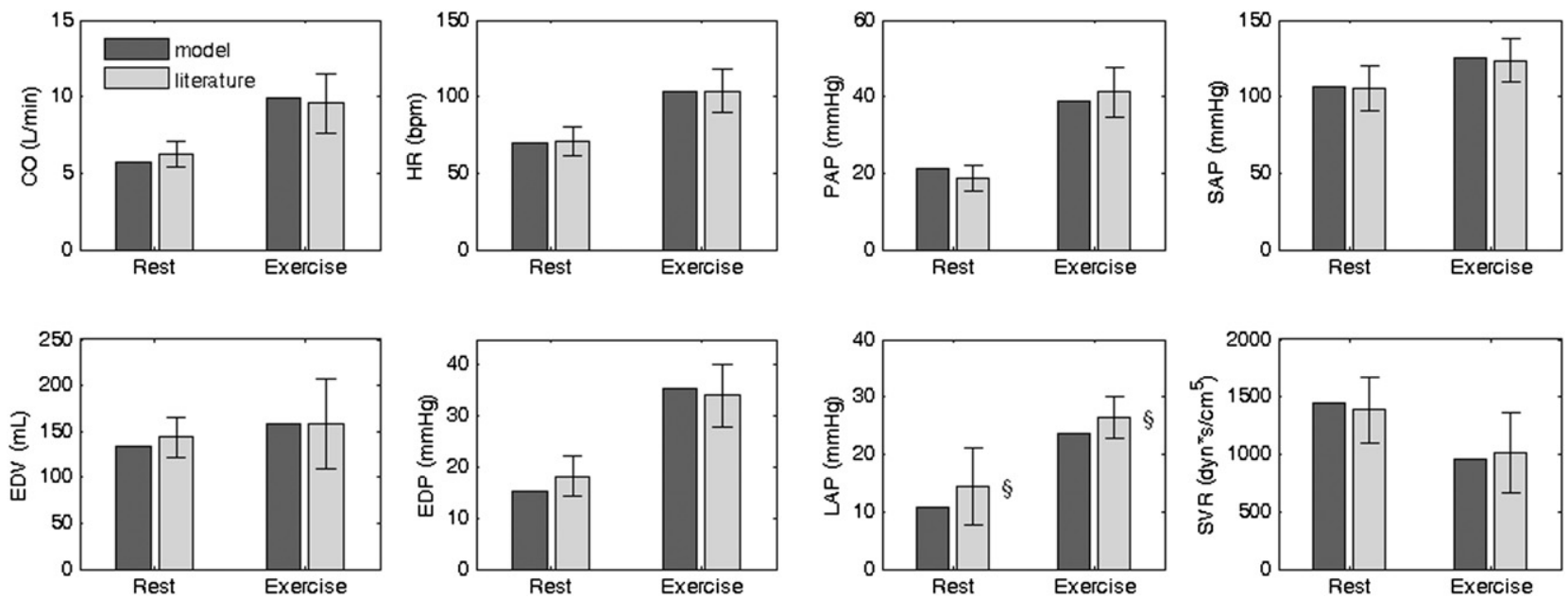

FIGURE 3. Comparison of the hemodynamic variables calculated from the simulation and the pooled published data. ${ }^{10-13,16,17,19-22}$ The pooled published

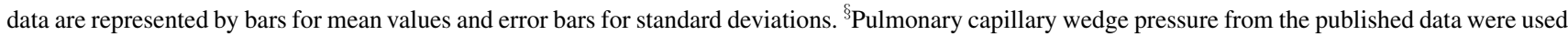
for comparison. $C O$, Cardiac output; $E D P$, end-diastolic pressure; $E D V$, end-diastolic volume; $H R$, heart rate; $L A P$, left atrial pressure; $P A P$, pulmonary arterial pressure; $S A P$, systemic arterial pressure; $S V R$, systemic vascular resistance. 

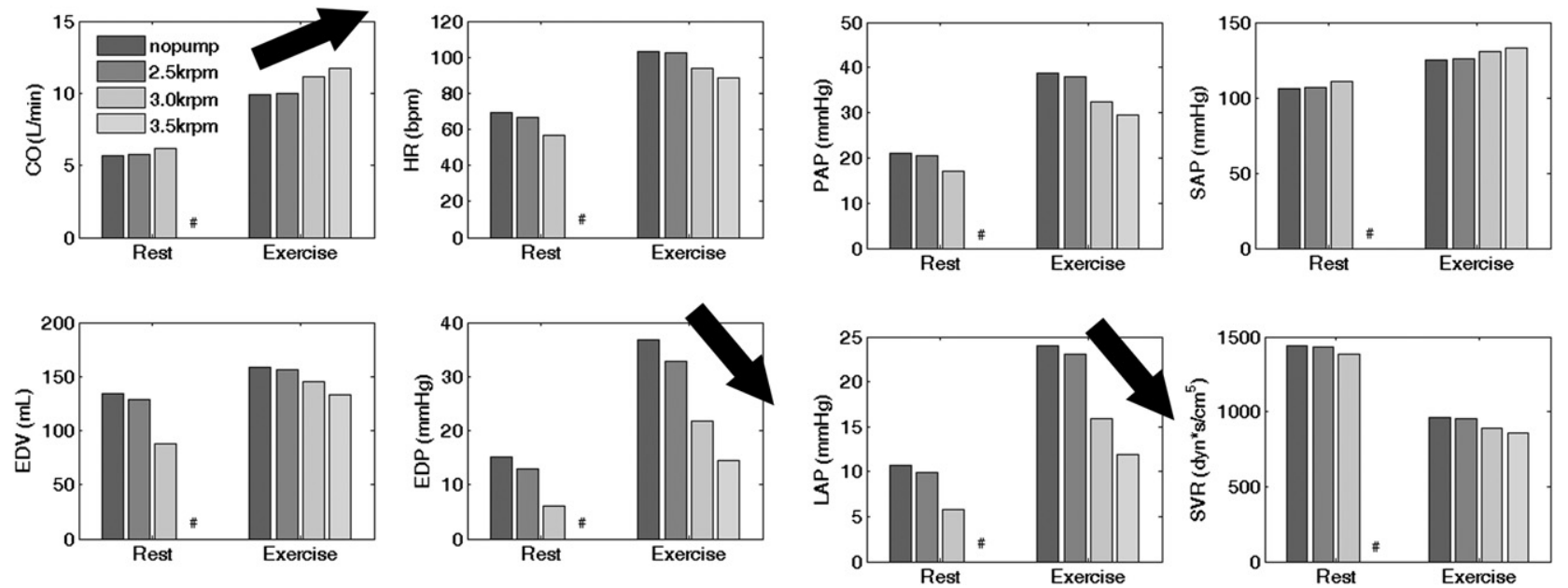

FIGURE 4. Hemodynamic changes induced by the continuous flow left ventricular assist device (CF-LVAD) running at 3 different speeds (2.5, 3.0 , and 3.5 $\mathrm{krpm}$ ) at rest and during exercise. Data for the unsupported condition are also shown (indicated as "no pump"). \#Complete empting of the left ventricular chamber and possible suction occurring at rest in the 3.5-krpm pump speed setting. During exercise, an increase in cardiac output $(C O)$ and a reduction in both end-diastolic pressure $(E D P)$ and left atrial pressure $(L A P)$ for increasing pump speeds (black arrows). EDV, End diastolic volume; $H R$, heart rate; $P A P$, pulmonary arterial pressure; $S A P$, systemic arterial pressure; $S V R$, systemic vascular resistance.

a reduction of the heart rate mediated by the baroreceptor reflex ( 88 vs 103 beats/min), together with a slight increase in the SAP (133 vs $125 \mathrm{~mm} \mathrm{Hg}$ ) and CO (11.73 vs 9.92 $\mathrm{L} / \mathrm{min}$ ).

\section{DISCUSSION}

CF-LVADs have proved in recent years to be a very good option to bridge patients with end-stage heart disease to transplantation, with survival rates approaching $70 \%$ to $80 \%$ in the first 2 years after implantation. ${ }^{1,2}$ This success triggered interest about the possible use of CF-LVADs even in less critical patients as partial support devices. ${ }^{24,25}$ The patients with HFNEF in the present study can also be considered as having less critical disease, being characterized by pronounced exercise intolerance but almost normal physical performance at rest (NYHA class II and III). The current treatment of these patients is aimed predominantly at symptom reduction, with a stilllimited increase in patient survival rates $(59 \%$ at 2 years after the heart failure diagnosis). ${ }^{3}$ To our knowledge, no systematic use of the CF-LVAD in these patients has been investigated and reported, but only in patients with NYHA class IV and a highly reduced ejection fraction. ${ }^{1,2}$ Obviously, the use of CF-LVADs in less sick patients is conceivable only if the mechanical assistance will prove to be advantageous compared with conventional treatment. Smaller and easier-to-implant CF-LVADs could eventually lead to similar or even better survival rates as those observed in patients with systolic heart failure, leading to an improvement in the current survival of patients with HFNEF. Additionally, it can be speculated that mechanical assistance could cause reverse remodeling or even pathology reversal, in the case of patients with HFNEF with hypertensive etiology. This consideration is based on the documented experience of partial regression of hypertrophy after stenotic aortic valve replacement ${ }^{26}$; thus, it is imaginable that the unloading performed by the CF-LVAD could contribute to an eventual reverse remodeling of the hypertrophic heart. It can also probably be assumed that CF-LVAD use for HFNEF could reverse the neurohormonal milieu derangement of heart failure and thus favor recovery. ${ }^{27}$

In the present study, however, we investigated the use of CF-LVAD and its effectiveness only with regard to the possible hemodynamic benefits for patients with HFNEF. The results from the simulation (Figure 4) showed that CF-LVAD assistance could increase the CO compared with the unassisted condition ( $\mathrm{CO}, 11.73$ vs $9.92 \mathrm{~L} / \mathrm{min})$ during physical activity. At the same time, it could also unload the left ventricle (EDP, 14 vs $35 \mathrm{~mm} \mathrm{Hg}$ ) and decrease the pulmonary circulation remarkably (LAP, 12 vs $24 \mathrm{~mm} \mathrm{Hg}$ ). This, altogether, would contribute to alleviate the symptoms and the marked exercise intolerance typical for patients with HFNEF, leading to an overall improvement in their quality of life. Similar to the case of CFLVAD use in those with systolic heart failure, 1 of the key benefits of mechanical assistance for diastolic heart failure is the improved Frank-Starling reserve of the left ventricle. This allows an increase in $\mathrm{CO}$, which is obtainable still at a low LAP and, therefore, pulmonary venous pressures, similar to the case of support in patients with systolic heart failure. ${ }^{5}$ In contrast to the case of CFLVADs in systolic heart failure, the present simulation suggests that in the case of HFNEF, a constant pump speed for the rest/exercise conditions is not advisable. The simulation data implied that the pump speed should be kept 
low at rest (owing to the risk of ventricular/atrial suction) and that speed should be then increased during exercise for the assistance to be effective in keeping the LAP and pulmonary pressure low. In particular, it can be observed in Figure 4 that a speed of $2.5 \mathrm{krpm}$ could be adequate at rest but completely ineffective during exercise, and a speed of $3.5 \mathrm{krpm}$ could lead to suction at rest but be adequate during exercise. For this reason, a constant speed strategy, such as is currently used for patients with systolic heart failure, would be ineffective or even counterproductive. The pump speed should be adapted to the physical activity, either by an automatic control that detects exercise and responds accordingly (such as occurs with rate-responsive pacemakers) by increasing the pump speed or using a system that allows manual changes of the pump speed.

In a recent study, a CF-LVAD was used in patients with restrictive and hypertrophic cardiomyopathy, ${ }^{28}$ demonstrating the technical feasibility of the implantation procedure and showing no difference in mortality compared with patients with dilated or ischemic cardiomyopathy treated with CF-LVAD. Although the patients included in the study by Topilsky and colleagues ${ }^{28}$ presented with an ejection fraction ranging from $20 \%$ to $36 \%$, and thus lower than the ejection fraction considered in the present study, interesting comparisons could be done. Similar to the present results, the data from Topilsky and colleagues ${ }^{28}$ showed that CF-LVAD led to a reduction in pulmonary pressures and right ventricular systolic pressure. Of the 8 patients initially with NYHA class IIIb or IV, 7 improved their functional class, showing better tolerance to physical activity, just as our simulation studies also suggested. From a clinical viewpoint, Topilsky and colleagues ${ }^{28}$ concluded that patients with restrictive and hypertrophic cardiomyopathy might benefit from CF-LVAD therapy but would require a more careful pump and fluid balance management and careful right heart monitoring. Accordingly, the simulation results also suggested that, especially at rest, suction could easily occur and that algorithms for the robust detection and prevention of suction would be necessary to avoid its occurrence. Suction might occur if the ventricular chamber dimensions are nearly normal and the pump flow exceeds the blood flow supplied by the venous return. Even if a stiffer ventricular wall would be less prone to suction, just as the experience during healthy animal tests suggests, suction could still occur in the atrium or pulmonary veins.

Some additional aspects and limitations of the present study should be considered.

Obviously, the present study could not address the clinical performances of CF-LVADs in patients with HFNEF but only the hemodynamic performances. The question of superiority of this method compared with pharmacologic therapy, the noninferiority of the safety profile, and the issues related to adverse events and improved patient survival remain unanswered and were beyond the scope of our study.
To address these questions and draw adequate conclusions about the use of CF-LVADs in this population, a randomized clinical study must be performed. The results from a first experience of CF-LVAD application in 8 patients with restrictive and hypertrophic cardiomyopathy compared with dilated and ischemic cardiomyopathy are encouraging, ${ }^{28}$ but they need to be confirmed in larger trials.

The model used was based on a careful review of the published data of patients with HFNEF without CF-LVAD support. ${ }^{10-13,16,17,19-22}$ Even if there is some deviation of the simulation results (eg, for the EDP and pulmonary capillary wedge pressure/LAP) from the average published data, the simulation results always remained within 1 standard deviation of the published data, which represents natural patient variability (Table 1 and Figure 3). This deviation does not signify a poor model representation of diastolic filling. The ventricular filling impairment was indeed reflected by the relative change in both EDV and EDP during exercise, with respect to the at rest condition (with a small volume increase associated with a considerable pressure increase). This aspect is very well reproduced by the model (Table 1 and Figure 3), thus proving an accurate presentation of the key hemodynamics of HFNEF. We are, therefore, confident that this model is a valid tool for elucidating the complex hemodynamic interaction between ventricular function and mechanical support. The use of hemodynamic models such as the one we have proposed have been demonstrated to be very useful in previous investigations of mechanical assistance and its interaction with the native heart. For example, in the study by Morley and colleagues, ${ }^{24}$ a hemodynamic simulation was used to investigate partial mechanical support in those with mild to severe cardiac failure, with the results confirmed by a subsequent clinical study. ${ }^{25}$ Another hemodynamic simulation was used to investigate the heart work during partial unloading and after removal of a CF-LVAD, ${ }^{6}$ with the results confirmed and further improved by subsequent animal experiments. ${ }^{29}$

The hemodynamic model did not include long-term adaptation mechanisms, such as the response to the reninangiotensin-aldosterone system, the dynamics of endothelial function and arterial stiffness, or the different degrees of autonomic dysfunction. These mechanisms must be considered for the investigation of potential neurohormonal and arterial (reverse) remodeling. However, the present study focused only on short-term hemodynamic changes due to mechanical assistance. Finally, the numeric model was validated against the data from patients with HFNEF that did not include a CF-LVAD. Therefore, the extrapolation performed by considering the CF-LVADs in the HFNEF model must undergo experimental in vivo and clinical validation. Nevertheless, the hemodynamic trends predicted by our simulation showed patterns similar to those reported by Topilsky and colleagues. ${ }^{28}$ 


\section{CONCLUSIONS}

The results of the present simulation study suggest that considerable hemodynamic benefits can be achieved with CF-LVAD use in patients with HFNEF. LV pump support can unload the pulmonary circulation, especially during physical activity, thus potentially alleviating the symptoms and the marked exercise intolerance typical for patients with HFNEF and, finally, leading to an improved quality of life. However, a constant speed strategy, such as is currently used for systolic heart failure assistance, is not advisable in those with HFNEF because of either an increased risk of suction at rest (if the speed is too high) or ineffective pulmonary unloading during exercise (if the speed is too low).

\section{References}

1. Slaughter MS, Rogers JG, Milano CA, Russell SD, Conte JV, Feldman D, et al; HeartMate II Investigators. Advanced heart failure treated with continuous-flow left ventricular assist device. $N$ Engl J Med. 2009;361:2241-51.

2. Kirklin JK, Naftel DC, Kormos RL, Stevenson LW, Pagani FD, Miller MA, et al. Third INTERMACS Annual Report: the evolution of destination therapy in the United States. J Heart Lung Transplant. 2011;30:115-23.

3. Owan TE, Hodge DO, Herges RM, Jacobsen SJ, Roger VL, Redfield MM. Trends in prevalence and outcome of heart failure with preserved ejection fraction. N Engl J Med. 2006;355:251-9.

4. From AM, Borlaug BA. Heart failure with preserved ejection fraction: pathophysiology and emerging therapies. Cardiovasc Ther. 2011;29:e6-21.

5. Zimpfer D, Zrunek P, Roethy W, Czerny M, Schima H, Huber L, et al. Left ventricular assist devices decrease fixed pulmonary hypertension in cardiac transplant candidates. J Thorac Cardiovasc Surg. 2007;133:689-95.

6. Schima H, Vollkron M, Boehm H, Röthy W, Haisjackl M, Wieselthaler G, et al. Weaning of rotary blood pump recipients after myocardial recovery: a computer study of changes in cardiac energetics. J Thorac Cardiovasc Surg. 2004;127: 1743-50.

7. Moscato F, Arabia M, Colacino FM, Naiyanetr P, Danieli GA, Schima H. Left ventricle afterload impedance control by an axial flow ventricular assist device: a potential tool for ventricular recovery. Artif Organs. 2010;34:736-44.

8. Klotz S, Hay I, Dickstein ML, Yi GH, Wang J, Maurer MS, et al. Single-beat estimation of end-diastolic pressure-volume relationship: a novel method with potential for noninvasive application. Am J Physiol Heart Circ Physiol. 2006;291: H403-12.

9. Burkhoff D, Sugiura S, Yue DT, Sagawa K. Contractility-dependent curvilinearity of end-systolic pressure-volume relations. Am J Physiol. 1987;252(6 Pt 2): H1218-27.

10. Zile MR, Baicu CF, Gaasch WH. Diastolic heart failure-abnormalities in active relaxation and passive stiffness of the left ventricle. $N$ Engl J Med. 2004;350: 1953-9.

11. Penicka M, Bartunek J, Trakalova H, Hrabakova H, Maruskova M, Karasek J, et al. Heart failure with preserved ejection fraction in outpatients with unexplained dyspnea: a pressure-volume loop analysis. J Am Coll Cardiol. 2010; 55:1701-10.
12. Westermann D, Kasner M, Steendijk P, Spillmann F, Riad A, Weitmann K, et al. Role of left ventricular stiffness in heart failure with normal ejection fraction. Circulation. 2008;117:2051-60.

13. Kasner M, Westermann D, Steendijk P, Gaub R, Wilkenshoff U, Weitmann K, et al. Utility of Doppler echocardiography and tissue Doppler imaging in the estimation of diastolic function in heart failure with normal ejection fraction: a comparative Doppler-conductance catheterization study. Circulation. 2007;116: 637-47.

14. Rowell LB. Human cardiovascular control. New York: Oxford University Press; 1993.

15. Ursino M, Magosso E. Role of short-term cardiovascular regulation in heart period variability: a modeling study. Am J Physiol Heart Circ Physiol. 2003;284: H1479-93.

16. Maeder MT, Thompson BR, Brunner-La Rocca HP, Kaye DM. Hemodynamic basis of exercise limitation in patients with heart failure and normal ejection fraction. J Am Coll Cardiol. 2010;56:855-63.

17. Borlaug BA, Nishimura RA, Sorajja P, Lam CS, Redfield MM. Exercise hemodynamics enhance diagnosis of early heart failure with preserved ejection fraction. Circ Heart Fail. 2010;3:588-95.

18. Moscato F, Danieli GA, Schima H. Dynamic modeling and identification of an axial flow ventricular assist device. Int J Artif Organs. 2009;32:336-43.

19. Kawaguchi M, Hay I, Fetics B, Kass DA. Combined ventricular systolic and arterial stiffening in patients with heart failure and preserved ejection fraction: implications for systolic and diastolic reserve limitations. Circulation. 2003;107: 714-20.

20. Drazner MH, Prasad A, Ayers C, Markham DW, Hastings J, Bhella PS, et al. The relationship of right- and left-sided filling pressures in patients with heart failure and a preserved ejection fraction. Circ Heart Fail. 2010;3:202-6.

21. Baicu CF, Zile MR, Aurigemma GP, Gaasch WH. Left ventricular systolic performance, function, and contractility in patients with diastolic heart failure. Circulation. 2005;111:2306-12.

22. Borlaug BA, Melenovsky V, Russell SD, Kessler K, Pacak K, Becker LC, et al. Impaired chronotropic and vasodilator reserves limit exercise capacity in patients with heart failure and a preserved ejection fraction. Circulation. 2006;114: 2138-47.

23. Hozo SP, Djulbegovic B, Hozo I. Estimating the mean and variance from the median, range, and the size of a sample. BMC Med Res Methodol. 2005;5:13.

24. Morley D, Litwak K, Ferber P, Spence P, Dowling R, Meyns B, et al. Hemodynamic effects of partial ventricular support in chronic heart failure: results of simulation validated with in vivo data. J Thorac Cardiovasc Surg. 2007;133:21-8.

25. Meyns BP, Simon A, Klotz S, Wittwer T, Schlensak C, Rega F, et al. Clinical benefits of partial circulatory support in New York Heart Association class IIIB and early class IV patients. Eur J Cardiothorac Surg. 2011;39:693-8.

26. Biederman RW, Magovern JA, Grant SB, Williams RB, Yamrozik JA, Vido DA, et al. LV reverse remodeling imparted by aortic valve replacement for severe aortic stenosis; is it durable? A cardiovascular MRI study sponsored by the American Heart Association. J Cardiothorac Surg. 2011;6:53.

27. Klotz S, Jan Danser AH, Burkhoff D. Impact of left ventricular assist device (LVAD) support on the cardiac reverse remodeling process. Prog Biophys Mol Biol. 2008;97:479-96.

28. Topilsky Y, Pereira NL, Shah DK, Boilson B, Schirger JA, Kushwaha SS, et al. Left ventricular assist device therapy in patients with restrictive and hypertrophic cardiomyopathy. Circ Heart Fail. 2011;4:266-75.

29. Ando M, Nishimura T, Takewa Y, Kyo S, Ono M, Taenaka Y, et al. Creating an ideal "off-test mode" for rotary left ventricular assist devices: establishing a safe and appropriate weaning protocol after myocardial recovery. $J$ Thorac Cardiovasc Surg. 2012;143:1176-82. 